[Agr. Biol. Chem., Vol. 29, No. 7, p. 696 697, 1965]

\title{
The Structure of a New Metabolite of Aspergillus versicolor
}

Sir:

In the previous communication ${ }^{11}$ we reported the structures of two pigments, versicolorin $A$ and versicolorin $B(I)$, which were isolated from mycelia of Aspergillus versicolor (Vuillemin) Tiraboschi. In addition to these compounds we subsequently isolated a new pigment, tentatively named versicolorin $\mathrm{C}$, through chromatography on silica gel. In purifying the pigments we met difficulty which seems to have arisen from the close relation of their structures. This communication is concerned with the structure elucidation of versicolorin $\mathrm{C}$.

Versicolorin $\mathrm{C}$ (II) is orange red needles, m.p. $>310^{\circ} \mathrm{C},\left[\alpha{ }_{\mathrm{D}}^{25} 0^{\circ}\right.$ (c. 0.44 in dioxane). Anal. Found: C, 63.55; H, 3.54; M.W., 332, 340 (osmometer). Calcd. for $\mathrm{C}_{18} \mathrm{H}_{12} \mathrm{O}_{7}: \mathrm{C}, 63.53$; H, 3.55\%; M.W., 340. $\lambda_{\max }^{\mathrm{E} \text { EOH }} 223(4.46), 255$ (4.20), 267(4.31), 292(4.46), 326(4.00), 450(4.03) $\mathrm{m} \mu(\log \varepsilon) . \nu_{\mathrm{max}}^{\mathrm{KBr}} 3410,1670,1625 \mathrm{~cm}^{-1}$. Methylation of II gave a trimethyl ether (III), m.p. $216^{\circ} \mathrm{C},[\alpha]_{D}^{25} 0^{\circ},[\alpha]_{i 90 \sim 600 \mathrm{m \mu}}^{25} 0^{\circ}$ (c O.80 in dioxane). Anal. Found: C, 65.95; H, 4.87; $\mathrm{OCH}_{3}, 24.10$; M.W., 386(osmometer), 380(Rast). Calcd. for $\mathrm{C}_{21} \mathrm{H}_{16} \mathrm{O}_{7}: \mathrm{C}, 65.96 ; \mathrm{H}, 4.75 ; \mathrm{OCH}_{3}, 24.28 \%$;
M.W., 382. $\lambda_{\max }^{\mathrm{EtOH}} 223(4.58), 285(4.58), 346(3.52)$ $410(3.51) \mathrm{m} \mu(\log \varepsilon) . \quad \nu_{\max }^{\mathrm{KBr}} \quad 1673,1660 \mathrm{~cm}^{-1}$ $\nu_{\max }^{\mathrm{CHCl}} 1665 \mathrm{~cm}^{-1}$ The NMR spectrum of II in deuterochloroform shows signals at 2.6: $\tau$ (singlet, $1 \mathrm{H}$ ); $2.69 \tau$ (doublet, $J=2.5$ c.p.s., $1 \mathrm{H}$ ) $3.26 \tau$ (doublet, $J=2.5$ c.p.s., $1 \mathrm{H}$ ); $3.63 \tau$ (dou blet, $J=6$ c.p.s., $1 \mathrm{H}$ ); $5.85 \tau$ (multiplet, $2 \mathrm{H}$ ) $5.95 \tau$ (singlet, $3 \mathrm{H}$ ); $6.02 \tau$ (singlet, $3 \mathrm{H}), 6.0$ $\tau$ (singlet, $3 \mathrm{H}) ; 6.35 \tau$ (multiplet, $1 \mathrm{H}), 7.7$ ? $\tau$ (multiplet, $2 \mathrm{H}$ ).

The infrared spectrum of II showed a non chelated carbonyl band at $1670 \mathrm{~cm}^{-1}$ and chelated carbonyl band at $1625 \mathrm{~cm}^{-1}$. The infrared spectrum of III showed a non-chelater carbonyl band at $1665 \mathrm{~cm}^{-1}$ and no band dur to the chelated carbonyl group. The ultra violet spectrum of II was similar to that 0 versicolorin $B, \lambda_{\max }^{\text {Etor }} 223(4.38), 255(4.13), 26 t$ (4.29) $291(4.38), 324(4.11), 450(3.94) \mathrm{m} \mu(\log \varepsilon){ }^{1}$ I, m.p. $298^{\circ} \mathrm{C}$ (decomp.), $[\alpha]_{\mathrm{D}}^{35}-223^{\circ}$ (c 0.42 is dioxane), has the molecular formula $\mathrm{C}_{18} \mathrm{H}_{12} \mathrm{O}_{7}{ }^{1}{ }^{1}$

Similarity of the ultraviotet spectra of II th I, besides their same molecular formulas, sug gests that both compounds would be ver closely related hydroxyanthraquinone. How

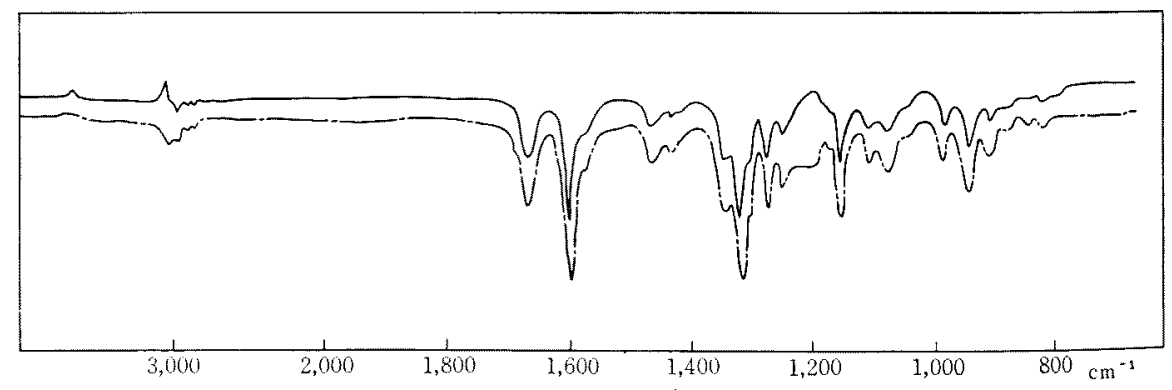

FIG. 1. Infrared Spectra (in $\mathrm{CHCl}_{3}$ )

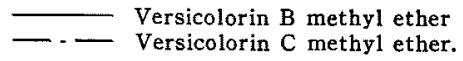

1) T. Hamasaki, Y. Hatsuda, N. Terashima and M.

Renbutsu, This Journal, 29, 166 (1965). 
ever, the difference can be seen in the melting points and optical properties. It is noticed that I is strongly levo-rotatory, whereas II is optically inactive.

The infrared spectra of II and I in Nujol showed close similarity except some slight differences. As both compounds are sparingly soluble in chloroform, the comparison of their infrared spectra was achieved using the solution of their methyl ethers, which gave superimposable spectra. The NMR spectrum of III in deuterochloroform gave a superimposable spectrum with that of methyl ether of I."

Thus, the above experimental evidences in-<smiles>O=C1c2cc(O)cc(O)c2C(=O)c2c1cc1c(c2O)C2CCOC1O2</smiles>

dicate that versicolorin $\mathrm{C}$ should be considered as a racemate of versicolorin $\mathrm{B}$. As racemization of I was not observed in isolating procedure, II may be a natural product.

We are grateful to Prof. S. Shibata, the University of Tokyo, for his interest and helpful suggestion. We also wish to thank Dr. O. Tanaka for discussion on nuclear magnetic resonance spectra.

\section{Takashi Hamasaki \\ Yuichi Hatsuda \\ Noritsugu Terashima* \\ Masayoshi Renbutsu}

Faculty of Agriculture

Tottori University

Tottori shi

*Faculty of Agriculture

Nagoya University

Anjo shi 